\title{
EL CURSO GARANTISTA DE LAS POLITICAS PÚBLICAS EN LA SOCIEDAD ECUATORIANA
}

\author{
THE GUARANTEE COURSE OF PUBLIC POLICIES IN ECUADORIAN SOCIETY
}

Adrian A. Alvaracin Jarrin ${ }^{1}$

\section{Resumen}

Ecuador se encuentra sumido en un modelo neoliberal de exclusión, que impone retos para el Derecho en general y una respuesta inexorable y específica desde el Derecho constitucional y el desarrollo de sus garantías políticas. En primer lugar, se refleja el cambio de paradigma en cuanto a los efectos desplegados por una sociedad neoliberal. Posteriormente se analiza de manera cualitativa las garantías constitucionales, específicamente las garantías políticas, pues son éstas y no otras las encargadas de limitar el abuso de poder e impedir el avance de políticas autoritarias y de ideologías que encubren formas de exclusión. Por último, una vez estudiados los efectos que trae consigo la ideología neoliberal y la manera de contrarrestarlos a través de un sistema de garantías políticas constitucionales, se elabora una respuesta aplicable al Ecuador. De este modo, se formula una Política pública de reducción de daños, aplicable al Ecuador y adecuada a su ordenamiento jurídico constitucional.

\section{Palabras clave}

Políticas públicas; Derecho constitucional; Garantías constitucionales; Neoliberalismo.

\section{Abstract}

Ecuador is immersed in a neoliberal model of exclusion, which imposes challenges for the law in general and an inexorable and specific response from constitutional law and the development of its political guarantees. In the first place, the paradigm shift is reflected in terms of the effects deployed by a neoliberal society. Subsequently, the constitutional guarantees are analyzed in a qualitative manner, specifically the political guarantees, since these are the ones that are responsible for limiting the abuse of power and preventing the advance of authoritarian policies and ideologies that conceal forms of exclusion. Finally, once the effects of neoliberal ideology and the way of counteracting them through a system of constitutional political guarantees are studied, a response applicable to Ecuador is elaborated. In this way, a public policy of harm reduction is formulated, applicable to Ecuador and appropriate to its constitutional legal order.

\section{Keywords}

Public Policies; Constitutional Rights; Constitutional Guarantees; Neoliberalism.

\footnotetext{
${ }^{1}$ Ministerio de Justicia. República del Ecuador. Correo electrónico: adrian_alvaracin.j@hotmail.com
} 


\section{Introducción}

En el entramado neoliberal que desregulariza el mercado, privatiza hasta los confines del alma y excluye a los desposeídos que no logran acceder al mercado del consumo, comparece una relación de indiferencia social entre incluido-excluido con un modelo de sociedad 80-20 (ochenta por ciento excluidos, veinte por ciento incluidos) (Martin \& Schumann, 1996). La diferencia esencial entre una sociedad industrial que la rastreamos hasta mediados del siglo pasado, con una sociedad de consumo, radica en que la primera usa al explotado para sus fines productivos, mientras que la sociedad hiperconsumista ya no necesita de la explotación de la fuerza laboral, sino que excluye, así "en el nuevo mundo de los consumidores, la producción masiva no requiere ya mano de obra masiva. Por eso los pobres, que alguna vez cumplieron el papel de ejército de reserva de mano de obra, pasan a ser ahora consumidores expulsados del mercado" (Bauman, 1999), reinando el "nuevo principio de la modernización (...) el downsizing (el achicamiento o reducción de personal)" (Bauman, 1999), convirtiendo a las personas en descartables sociales, fácilmente reemplazables e innecesarios, lo que le permite desplegar su arsenal de dominación de manera fluida.

Cuando el poder del mercado se instala en los intersticios de la sociedad, se hace casi imposible volver la mirada al ser humano. Max Weber desde inicios del siglo pasado alertaba sobre las consecuencias de una sociedad regida por el mercado, que dominaba todos los actos de las personas. El mercado es la relación de vida más impersonal en la que el ser humano puede entrar (Weber, 2014), de esta manera es el capital y el intercambio el que domina en el escenario del desarrollo social, centrándose en las cosas y no en la persona. Todo se explica en términos del mercado, las relaciones se tornan impersonales y si se vuelve la mirada hacia el individuo, la cuestión será sólo para evaluar su éxito personal y otra vez en torno a su producción dentro del mercado.

La individualización a la que lleva el neoliberalismo y su libre mercado impide que valores socialmente adecuados, como el compromiso, el bien común, la reivindicación de derechos (laborales, económicos, minorías, etc.) se vean mermados ante el inmenso arsenal de ideología impuesta desde los fines del mercado, con el fin de mantener el establishment (entendido como el grupo social que impone y mantiene el orden establecido) requiriendo el control de esa inmensa población de excluidos que han sido expulsados del consumo e incluso marginados de los derechos fundamentales. Es así que a continuación se explica de manera descriptiva-crítica este nuevo modelo de sociedad, tratando de hallar los insumos para una Política pública de reducción de daños, pues el Derecho constitucional debe enfrentar aquél marco planetario de poder denominado globalismo, el cual genera exclusión en nuestros pueblos latinoamericanos. Para la finalidad expuesta, las garantías constitucionales y los derechos fundamentales son necesarios como instrumentos invaluables en el camino por encontrar una Política garantista que preserve la dignidad de aquellas culturas alternativas de los excluidos, logrando contener los abusos del poder y las injusticias.

\section{Tesis de la reflexión}

El neoliberalismo impide el desarrollo de una política pública garantista acorde al ordenamiento jurídico constitucional del Ecuador.

\section{Desarrollo}

El neoliberalismo encubre una exclusión latente. En el Ecuador, durante los últimos años, hemos apreciado una inclinación por parte del Estado hacia la privatización, la flexibilización y el control de la criminalidad mediante lo denominado como mano dura. Esto ha ocasionado que por ejemplo el desempleo aumente (El Comercio, 2019) (políticas de flexibilización) o que el número de presos en el Ecuador se dispare de manera alarmante, llegando según cifras del Servicio Nacional de Atención Integral a Personas Adultas Privadas de la Libertad y Adolescentes Infractores al $40 \%$ de hacinamiento en el país (La Hora, 2019), lo que demuestra que existe una política criminal de mano dura que se inserta dentro de todo el enjambre neoliberal. Lo que está en juego en este entramado neoliberal es la exclusión de aquellas personas que por su situación de vulnerabilidad son alejadas de aquellas políticas de flexibilización o atrapadas por las políticas criminales de mano dura.

El neoliberalismo como sostiene Klein (2017): “(...) es la expresión taquigráfica de un proyecto económico que denigra la esfera de lo público y cualquier cosa que no sea producto, o bien del funcionamiento del mercado, o de las decisiones individuales de los consumidores", dejando de lado la participación del Estado. Es la receta que se aplicó por los años 70 durante las dictaduras en la región. Activa contribución y manejo de la República (cosa pública) 
por parte del sector privado y nula intervención estatal; de esa manera se podría resumir el modelo neoliberal capitalista.

Como toda ideología, la neoliberal oculta y encubre su función política como mero justificativo para el ejercicio del poder (Ávila, 2019). Así, lo que pretende la ideología neoliberal es imponer su modelo de exclusión, pobreza y apartheid a través de la hegemonía que ostentan reducidos grupos de poder financiero, quienes ejercen en la actualidad el poder y la soberanía de los Estados a través del endeudamiento masivo, el cual se ha convertido en el arma de que se vale el totalitarismo financiero (Zaffaroni \& Días Dos Santos, 2019). Esta realidad que presenta el poder puede ser subvertida a través de los derechos tomados en serio, mediante una decisión política de proponer, aplicar y desarrollar integralmente las garantías constitucionales en la esfera de las políticas públicas.

Por ejemplo, existe escasez de lo más elemental, así como desnutrición, pobreza, lo que torna a nuestras sociedades desiguales e inequitativas. En nuestra región la desigualdad descrita se puede verificar empíricamente a través del Coeficiente de Gini, que es un indicador el cual mide el grado de desigualdad en la distribución de riqueza en los países, así mientras el valor se aproxime a 0, el país es menos desigual o se acerca a la igualdad plena. De esta manera tenemos que en el año 2017 el coeficiente de Gini en Ecuador, según el INEC, obtuvo un resultado de 0,47(INEC, 2018), mientras que en países como Noruega, que mantienen sus reservas respecto de políticas neoliberales, el porcentaje se ubica en 0,27 (Banco Mundial, 2018).

Pues bien, ¿ cómo se contrarrestaría esta realidad a través del Derecho o de los derechos? Si no se toma conciencia sobre esa realidad, entonces se necesita del derecho y el acceso a la información para poder develar lo que encubre una ideología. Para que ese derecho no se mantenga en un nivel enunciativo, se necesita de instituciones que garanticen el acceso real a esa información. En otras palabras, primero implementamos los derechos y luego los garantizamos a través de una Política pública.

Se cree que el neoliberalismo proviene de dos voces que son neo y liberalismo. Pretende presentarse como un nuevo liberalismo para esta época. El neoliberalismo no guarda relación con el liberalismo originario producto de la burguesía en ascenso con la llegada de la Revolución Industrial en el siglo XVIII. Existen innumerables consideraciones que diferencian radicalmente el liberalismo del neo-liberalismo, pero considero que lo más grave que propugna el neoliberalismo es el repudio a los Derechos Humanos (Zaffaroni \& Días Dos Santos, 2019).

En esa línea, son sus ideólogos quienes han implementado ese rechazo, encontrándose entre ellos Milton Friedman, Ludwig von Mises y Friedrich von Hayek, los dos últimos personajes han sido citados y difundidos muchas veces por varios economistas a nivel regional y mundial. Su propuesta se basa en dos ejes: la negación de persona a todo ser humano, pues para von Mises la condición de humano no implica directamente la condición de persona (von Mises, 1995), resquebrajando totalmente el principio de igualdad y no discriminación, haciendo hincapié además en que nuestros pueblos son subdesarrollados por no adecuarse correctamente a las demandas del mercado, dejando con esto indemne al totalitarismo financiero respecto de la miseria de dos tercios de la población mundial. El segundo eje lo configura von Hayek: la separación entre libertad política y libertad individual. Para von Hayek no hay libertad sin libertad del mercado (von Hayek, 2011), lo que se traduce a manera de ejemplo en que un dictador por más cruel que sea, puede gobernar de manera liberal si el dictador implementa un modelo de libre mercado (Zaffaroni \& Días Dos Santos, 2019). Entonces tenemos que la tendencia de esta ideología es aniquilar la democracia (Zaffaroni \& Días Dos Santos, 2019) y los derechos humanos.

La idea del libre mercado es la constante en una sociedad neoliberal. Los efectos de esta ideología en su función política se traducen en que el empleo y subempleo alcanzan tan solo a un tercio de la población económicamente activa en todo el mundo, mientras que la mitad de la población vive con menos de dos dólares al día (Rajland, 2018), pues la lógica es que el mercado se autorregule, relegando a las personas como simples instrumentos al servicio del capital. Esto en cuanto a la esfera económica. Pero la ideología alcanza a toda la esfera política como gobierno de la polis. El recorte de presupuesto mediante los denominados ajustes, anulación de las conquistas de grupos sociales como la reivindicación de derechos, el acceso a una vivienda digna, el ocaso de las reivindicaciones sociales, la discriminación de grupos étnicos, la generación de pobreza, inseguridad y la acentuación de inequidades y desigualdades, sumadas al rápido deterioro del medio ambiente, la extinción de especies, la contaminación de la biosfera y podríamos continuar. La reivindicación de los 
derechos fundamentales ha sido una conquista llevada a cabo por largos años de lucha social, todo lo cual se ha dejado de lado por las políticas de carácter neoliberal que se definen como una serie de destrucciones del actuar colectivo de la humanidad (Houtart, 2001).

Una alternativa a este entramado neoliberal, la podemos encontrar en el Derecho constitucional, mediante estrategias, técnicas y tácticas específicas que blinden a las personas y a las instituciones de los embates que la globalización intenta penetrar en nuestros países a través de su ideología neoliberal, generando una deshumanización por exclusión económica y social.

Una garantía específica podría trazarnos el camino de la liberación: la garantía del derecho a la dignidad, que comprende y enmarca muchos otros derechos, como el respeto a la vida, a la seguridad, a la libertad de elección y a la autodeterminación de los pueblos. Esta garantía se enmarca en un método axiológico destinado a la transformación. Para esta construcción, los derechos fundamentales y las garantías constitucionales son herramientas poderosas para el empoderamiento de nuestros pueblos en su lucha por la emancipación y la liberación.

Para Ferrajoli, la conquista más importante del derecho contemporáneo ha sido "la regulación jurídica del derecho positivo mismo, no solo en cuanto a las formas de producción sino también por lo que se refiere a los contenidos producidos" (Ferrajoli, 1992), lo que ha ocasionado que nuestro ordenamiento jurídico asegure de manera reforzada los derechos fundamentales en la Constitución y para ello se vale de garantías que pueden ser: a) garantías políticas; b) garantías orgánicas; c) garantías jurisdiccionales o d) garantías supraestatales o internacionales.

En este estudio se toma partida de las garantías políticas. La idea central es que podemos lograr grandes avances a través de una verdadera política de reducción de daños, que logre proteger el contenido esencial de los derechos de las personas o la esfera de lo indecidible en palabras de Ferrajoli. Para este fin es necesario "incluir también normas sustanciales como el principio de igualdad y los derechos fundamentales, que de modo diverso limitan y vinculan al poder legislativo excluyendo o imponiéndole determinados contenidos" (Ferrajoli, 1992).

Vincular al poder en torno a los derechos se consigue mediante garantías políticas que impriman el qué hacer y qué no hacer por parte del Estado, con el fin de contener el avance de aquellas políticas que excluyen. Las garantías políticas pretenden des-cubrir y contrarrestar los efectos de una política que excluye. Por ello se denominan políticas de reducción de daños. Mientras una política criminal actúa con represión, una política de reducción de daños actúa en el nivel de la prevención.

Ejemplifiquemos esta idea sobre una política de reducción daños. René se inyecta heroína, René es adicto y ha ocasionado disturbios en el barrio en el que vive. Los vecinos están molestos, René es un problema para todo el barrio, vende droga, se inyecta, frecuenta prostíbulos, no trabaja, en fin, representa un peligro. Los moradores del barrio creen que la solución pasa por encerrar a René y olvidarse de él. En efecto, a la más mínima infracción la policía lo detiene, un tribunal lo juzga e ingresa a la cárcel. En la cárcel, René aprende otras formas delictivas, sale deteriorado, ahora sabe dónde conseguir droga más barata, de vez en cuando roba con violencia. René vuelve al barrio que lo vio crecer. Aprendió una mejor manera de vender droga sin ser detectado, odia a la gente a su alrededor porque ellos lo metieron en el infierno y un día de los tantos, René sale a buscar su mercancía, pero entonces se da cuenta que el dinero no le alcanza. René quien contrajo VIH en la cárcel, sale a robar para conseguir el dinero que le permita comprar droga. René en el forcejeo con la víctima, la mata.

Ahora se han generado dos graves problemas, René como consumidor y asesino, además de la víctima. Por un lado la ideología neoliberal del mercado presenta una vida de lujos que nuestros barrios precarios anhelan obtener (lo que se conoce como mímesis) y para ello cometen delitos, aunque no son los únicos que cometen delitos, pues las grandes organizaciones financieras los cometen a gran escala, pero son los ellos como René quienes ingresan a la cárceles; por otro lado, la política criminal de mano dura encerró a René, agravando el problema para él y la sociedad. Aquí se puede analizar la ideología neoliberal y una política criminal de mano dura.

Bien, ¿qué habría hecho la política garantista de reducción de daños? El mejor ejemplo lo encontramos en Portugal. En el país europeo desde el 2001 ha implementado una política de reducción de daños en cuanto a los consumidores de droga. Para ellos no hay cárcel, sino tratamiento. El consumo de droga es una enfermedad que puede ser tratada y con paciencia puede ser también curada, convirtiéndose en asunto de salud pública y no 
de prisión. Desde que se despenalizó el consumo y se dio tratamiento a los consumidores, los indicadores precisan que el consumo, el contagio de VIH, la muerte por sobredosis y la delincuencia relacionada con estupefacientes disminuyó drásticamente (RT, 2018). Vemos entonces que Portugal tomó en serio la dignidad de esas personas, las acogió, interpretó sus carencias y molestias y las transformó. Eso hace una política de reducción de daños.

$v$

Los derechos en este escenario son imprescindibles, pues en una sociedad inequitativa como la nuestra, las violaciones a derechos son cotidianas, por tanto, el Estado y todo órgano con competencia para conocer dichas violaciones deben tener en cuenta que "(...) los derechos no solo se violan por acciones -actos de agresión- sino que también se violan por omisión, - se violan por la omisión de dar a los demás la ayuda o los recursos que son necesarios para desarrollar una vida digna y autónoma" (Nino, 1989), de aquello se deduce que los derechos sociales no se contraponen a los derechos individuales sino que los primeros aparecen como extensión de los segundos, consiguiendo mayor alcance de protección.

Conforme lo expuesto, las garantías de los derechos fundamentales esbozan toda una estrategia capaz de controlar el avance de políticas neoliberales, pues su aplicación implica la protección por parte del Estado hacia sus ciudadanos en tanto los derechos sean violados por acción u omisión. Nuestra Carta Fundamental en el numeral 4 del Art. 11 (Constitución del Ecuador, 2008) prevé el contenido esencial de los derechos, entendido como aquella garantía frente al legislador, pues bajo este precepto ninguna norma o política pública puede restringir derechos, en otras palabras, si se viola el contenido esencial se viola directamente la Constitución. Todo este cúmulo de derechos y garantías que se han expuesto, logran proteger a los ciudadanos en una sociedad cada vez más exclusiva y menos incluyente. La solución se encamina por tomar en serio los derechos esenciales.

Como ha quedado señalado, es necesaria una política pública que resguarde y garantice derechos, para ello es necesaria la protección de bienes humanos como política garantista, que es la línea que se viene desarrollando. Empero, para que esta idea sea realmente plasmada, se necesita del Estado de Derecho, y por ende, de un sistema político democrático como Estado incluyente. Si el entramado neoliberal proyecta una sociedad 8020 (ochenta por ciento excluidos y veinte por ciento incluidos), los límites y vínculos que se impongan a los poderes públicos deben darse en la línea del respeto y protección de los bienes humanos, como los denomina Finnis (Vigo, 2007), que son "una esfera de aquello que es -no decidible- por parte de ninguna mayoría" (Ferrajoli, 2006), lo que abriría espacios de toma de decisiones para los excluidos, permitiendo evaluar de manera real el contenido de las decisiones de aquellos poderes públicos que implementan o crean políticas dirigidas a los sectores sociales vulnerables.

La protección de la esfera de lo -no decidible- implica por tanto una nueva concepción del Derecho, significa reconocer que "hay algo jurídico cognoscible que vale como tal, aunque no se lo haya reconocido o dispuesto socialmente"(Vigo, 2007), lo que impone al Estado y sus órganos de gobierno el reconocimiento de aquello que es indisponible en su accionar: la dignidad humana. El neoliberalismo no es ajeno al Ecuador ni mucho menos son ajenas sus políticas en el ámbito económico y sociocultural. Desde el gobierno de León Febres Cordero (19941998) (Foros Ecuador, 2019) hasta la actualidad con el gobierno de Lenín Moreno, el país se encuentra sumido en políticas de tinte neoliberal, las cuales despliegan, entre varios efectos, los siguientes: 1) Se conforma un Gabinete en donde los Ministros son representantes directos de grupos empresariales; 2) Se otorga la remisión de deudas tributarias y patronales a los grandes grupos económicos; 3) Ampliación de la flexibilización laboral y el despido de funcionarios públicos; 4) La sumisión de la política monetaria a la banca privada; 5) La reinstalación de tratados bilaterales de inversión que debilitan al Estado frente al capital extranjero, lo que ocasiona una apertura y entreguismo por parte del Estado a la inversión extranjera; 6) La continua explotación del ITT, lo cual genera estragos para las poblaciones no contactadas (Acosta \& Cajas, 2018), medidas cuyo desenlace son los efectos comentados, para lo cual se torna necesario contener a esas políticas mediante los derechos fundamentales.

A manera de ejemplo, figuremos que el Estado decide explotar el petróleo de una zona protegida en la Amazonía, lo cual en suposición generará riqueza para las arcas fiscales, pero pobreza, marginación y exclusión para los pueblos no contactados de la zona. En este ejemplo el Estado debe abstenerse de actuar, por dos razones: 1) Porque el contenido de su decisión es inconstitucional al afectar derechos fundamentales, como el derecho a la vida, a un ambiente sano o la autodeterminación de los pueblos, con mayor razón si no efectúa una consulta previa y, 2) 
Afecta directamente bienes humanos que son la "esfera de lo no decidible", por cuanto "ninguna mayoría ni siquiera unanimidad, puede legítimamente decidir la violación de un derecho de libertad o no decidir la satisfacción de un derecho social" (Ferrajoli, 1992), así al afectar a la población se vulnerarían derechos fundamentales y las políticas neoliberales se ampliarían, lo cual atenta contra la convivencia horizontal de la sociedad.

Garantías liberales (derechos de libertad) y garantías sociales (derechos sociales) son esenciales para la protección de derechos, pues ambas logran darle efectividad a los derechos fundamentales como "una cuestión de grado, que depende de la precisión de los vínculos positivos o negativos impuestos a los poderes públicos por las normas constitucionales y por el sistema de garantías que aseguran una tasa más o menos elevada de eficacia a tales vínculos" (Ferrajoli, 1992), lo que se traduce en que la medida de una verdadera democracia tiene su base en la gradualidad con la que vincula al Estado respecto de la protección de derechos fundamentales.

¿Pero dónde se encuentran esos derechos fundamentales? Ellos se encuentran en los instrumentos de Derechos Humanos, cuya positivización en la legislación internacional se halla plasmada en la Declaración Universal de Derechos Humanos adoptada por la Asamblea General de las Naciones Unidas en el año de 1948 ("Declaración Universal de Derechos Humanos," 1948), la misma que se dio como resultado de la empresa genocida de la Segunda Guerra Mundial. Se conoce bien que el mero hecho de una declaración no mejora directamente la vida de las personas y por ello éstos derechos deben tener un valor programático.

Entregarles valor programático significa otorgarles una función para su efectivización. El mandato de considerar a todo ser humano como persona es la principal función de los derechos humanos con su valor programático como respeto mínimo de la dignidad de las personas. El Ecuador ha encontrado la manera de plasmar los Derechos Humanos en lo más alto de la jerarquía de su ordenamiento jurídico: la Constitución (Título II). El país no solo adecuó la Declaración Universal de Derechos Humanos, sino que incluyó además los derechos de la naturaleza o Pacha Mama (Art.71), lo cual fortalece un Estado plurinacional e intercultural, además de avanzar en gran medida respecto de la protección de derechos de toda la vida que se desarrolla con nosotros.

La función de los derechos humanos en el país debe ser heurística (Zaffaroni, 2015) comprendiendo las necesidades que nos impone nuestra realidad. Para ello las garantías políticas son un eje donde debe primar la implementación de cada derecho y su garantía de protección reforzada. Se pretende lograr la realización social efectiva de los derechos fundamentales en el Ecuador para luchar contra las formas de dominación del actual momento planetario, adquiriendo prioridad la dignidad humana mediante el respeto a los derechos humanos y de la naturaleza.

Así la cuestión, nuestro país se encuentra confrontado entre dos modelos de Estado: uno incluyente, democrático, redistributivo, igualitario, independiente y con justicia social, y un estado excluyente, autoritario, no redistributivo, desigualdad extrema, dependencia del mercado. Para insertarnos en el primero es necesario entender que la Constitución y sus garantías políticas establecen un deber ser que puede llegar a ser a través de tres presupuestos que permiten analizar el desarrollo y cumplimiento dela realización constitucional. Imaginemos tres gradas y en la parte superior al culminar el camino se encuentra el Estado incluyente. Esas gradas contienen en cada escalón una regla o medida para verificar que el Estado incluyente se vaya realizando conforme los preceptos constitucionales. Estas tres gradas o escalones son: la Constitución, la realidad constitucional y el grado de realización constitucional.

La Constitución establece, como dijimos, el deber ser donde se han subsumido los derechos fundamentales y las garantías. La realidad constitucional se mide por el aporte de los datos que arroje la realidad a través de una investigación sociológica, permitiendo valorar la realización constitucional, es decir el grado de realización de esas normas en la realidad, es la verificación del ser social a modo de juicio de lo establecido y prescrito por la Constitución (Zaffaroni, 2015), para esta tarea la obvia garantía que debe primar es la garantía política, pues son éstas las que trabajan con el ser y la realidad. En fin, en el Estado incluyente cada institución del Estado propende a la efectiva realización de los derechos y las garantías constitucionales cuya medida se verifica en las tres premisas enunciadas.

Por ejemplo, la Constitución (primera grada) determina que el derecho al trabajo garantiza a los trabajadores el pleno respeto a su dignidad con remuneraciones y retribuciones justas (Constitución del Ecuador, 2008), entonces podemos subir seguros por esa grada, 
apoyándonos de la premisa constitucional. Ahora vamos a la realidad constitucional (segunda grada), en ella tambaleamos, y observamos que en la realidad muchas empresas mantienen a sus trabajadores por más de tres años a prueba y luego los despiden sin indemnización, ni bonificación, así como nos percatamos de que las remuneraciones son injustas. Entonces, resbalamos de la segunda grada y no existe realización constitucional del Art. 33 (tercera grada), así como tampoco vivimos en un Estado incluyente, porque las garantías constitucionales no se cumplen en la realidad ecuatoriana. Como conclusión, tenemos que el Ministerio del Ramo, institución encargada de velar por el derecho de los trabajadores, ha incumplido con su garantía política de asegurar la primera grada (Constitución), por tanto, se deberá reevaluar su funcionamiento e implementar políticas que puedan permitir la realización constitucional del Art. 33 de la Carta Fundamental.

Las preguntas que surgen son ¿cómo medir esas gradas? ¿De qué manera se efectivizan? En cada una de estas gradas debe vivir el impulso "hacia la realización de la norma básica de la antropología constitucional (concepto constitucional del ser humano): todo ser humano es persona, nacemos con igualdad de dignidad y derechos" (Constitución del Ecuador, 2008), lo que produce que se mida a la realización constitucional, respondiendo siempre a la dignidad humana.

Es menester en este desarrollo traer a colación el Art. 85 de la Constitución que determina la "formulación, ejecución, evaluación y control de las políticas públicas" (Constitución del Ecuador, 2008). En este artículo se establecen tres numerales en los cuales podemos apreciar todo un programa de política garantista de reducción de daños que se ha esbozado hasta este punto.

Así, el numeral uno del artículo 85 establece: "Las políticas públicas y la prestación de bienes y servicios públicos se orientarán a hacer efectivos el buen vivir y todos los derechos, y se formularán a partir del principio de solidaridad" (Constitución del Ecuador, 2008). Este numeral se relaciona con la efectivización de derechos fundamentales destinados a hacer realidad el buen vivir o el Estado incluyente bajo el principio de solidaridad, que implica la fraternidad entre personas y la naturaleza.

El numeral dos señala: "Sin perjuicio de la prevalencia del interés general sobre el interés particular, cuando los efectos de la ejecución de las políticas públicas o prestación de bienes o servicios públicos vulneren o amenacen con vulnerar derechos constitucionales, la política o prestación deberá reformularse o se adoptarán medidas alternativas que concilien los derechos en conflicto" (Constitución del Ecuador, 2008). La política aplicada hasta ahora, como por ejemplo las privatizaciones, las políticas criminales de mano dura o cualquier política neoliberal debe ser evaluada y si afecta derechos, debe ser reformulada o adoptar medidas alternativas que precautelen los derechos fundamentales de las personas a quienes va dirigida dicha política, recordemos el ejemplo del caso de drogas en Portugal.

Por último, el numeral 3 determina: “El Estado garantizará la distribución equitativa y solidaria del presupuesto para la ejecución de las políticas públicas y la prestación de bienes y servicios públicos" (Constitución del Ecuador, 2008). En este numeral se aprecia que el destino del presupuesto es la redistribución en favor de ejecución de políticas públicas que salvaguarden y efectivicen derechos, así como resguardar bienes y servicios públicos destinados a la protección de las personas excluidas.

El nuevo paradigma de las políticas públicas se ubica en el nivel de garantizar los bienes humanos de todas las personas. En este paradigma del constitucionalismo queda por discutir la función misma del Derecho y la justicia. En este modelo garantista, las políticas neoliberales no tienen cabida porque las mismas niegan abiertamente los derechos humanos, la dignidad de las personas y prevalece al mercado por sobre las personas. En el garantismo descansa un deber ser destinado a la dignidad de toda persona cuyo fundamento lo encuentra en la realización constitucional.

Entonces la política de reducción de daños será liberadora, democrática y humana, reconociendo el status de persona a todo ser humano y garantizando que sus demandas y derechos sean escuchados por las instituciones encargadas de brindarles protección, que en el Ecuador son todas, sin excepción. El constitucionalismo se encamina a la construcción de un Estado incluyente.

\section{Conclusión}

Hemos demostrado que el neoliberalismo impide llevar a cabo todo un programa de política garantista de derechos que se adecue al ordenamiento jurídico ecuatoriano. A partir de esa demostración, se formuló otra tesis, según la cual el Estado de Derecho debe, por imperativo constitucional, vincular su accionar en los derechos fundamentales mediante una política pública de reducción de daños. Sin aquella premisa no es posible encontrar 
un Estado de derechos y justicia. Así mismo, dicha vinculación puede darse en el contexto del garantismo donde lo no decidible sea base de una democracia efectiva.

El contenido esencial de los derechos que encontramos en el numeral 4 del Art.11 de la Constitución impide que cualquier política pública menoscabe derechos de las personas, además su formulación se encuentra programada en el Art.85 de la Norma Suprema. Estos derechos fundamentales, se erigen como base para formular cuestionamientos a las decisiones del poder, precisamente en las políticas que se destinen para nuestra convivencia como sociedad. Con esta premisa se torna insostenible propugnar políticas de tinte neoliberal.

Una política pública de reducción de daños que propenda a la liberación de los excluidos, toma en serio el diálogo como herramienta, por lo cual el Estado debe dirigir todos sus esfuerzos a escuchar sus peticiones, sus reclamos, en fin, sus derechos. En la misma línea, el Derecho constitucional debe garantizar derechos y a través de la política lograr encaminar la realización constitucional en el plano del ser, a través de la Constitución, su realidad y su efectivización. Los órganos del poder deben abstenerse de implementar políticas públicas que menoscaben derechos o garantías de su población. Una política que se encuentre en sintonía con el paradigma constitucional, es la principal alternativa.

\section{Referencias}

1. Acosta, A., y Cajas, J. (2018). Moreno, un neoliberal más. Displonible en https://lalineadefuego. info/2018/09/04/moreno-un-neoliberal-mas-poralberto-acosta-y-john-cajas-guijarro/

2. Ávila, R. (2019). La Utopía del Oprimido. México: AKAL

3. Banco Mundial. (2018). índice de Gini. Disponible en: https://datos.bancomundial.org/indicador/ SI.POV.GINI

4. Bauman, Z. (1999). Trabajo, consumismo y nuevos pobres. Barcelona: Gedisa.

5. Organización de las Naciones Unidas (ONU) (1948). Declaración Universal de Derechos Humanos. Disponible en: https://www.ohchr.org/ EN/UDHR/Documents/UDHR_Translations/spn. pdf

6. El Comercio. (2019). 261.767 personas perdieron su empleo adecuado en el último año, según INEC. Disponible en: https://www.elcomercio.com/ actualidad/inec-desempleo-subempleo-ecuadormarzo.html

7. Ferrajoli, L. (1992). El derecho como sistema de garantías. Nuevo foro penal, 60, 59-75.

8. Foros Ecuador. (2019). El Neoliberalismo en el Ecuador - Causas, consecuencias y características del Modelo Neoliberal. Disponible en: $\quad \mathrm{http}: / / \mathrm{www}$.forosecuador.ec/forum/ ecuador/educaci\%C3\%B3n-y-ciencia/178816el-neoliberalismo-en-el-ecuador-causasconsecuencias-y-caracter\%C3\%ADsticas-delmodelo-neoliberal

9. Ferrajoli, L. (2002). Derechos y garantías. La ley del más débil. Madrid: Trotta.

10. Houtart, F. (2001). Intervención del autor en la reunión del Consejo Internacional del Foro Social Mundial. Sao Paulo, 9 - 11 de junio de 2001.

11. INEC. (2018). Reporte de pobreza y desigualdad. Retrieved July 30, 2019, from https://www. ecuadorencifras.gob.ec/documentos/webinec/POBREZA/2018/Junio-2018/Informe_ pobreza_y_desigualdad-junio_2018.pdf

12. Klein, N. (2017). Decir no no basta. Barcelona: Paidós.

13. La Hora. (2019). Cárceles en Ecuador: seguridad, hacinamiento e infraestructura se atenderán en emergencia. Retrieved July 29, 2019, from https://lahora.com.ec/noticia/1102245677/ carceles-en-ecuador-seguridad-hacinamiento-einfraestructura-se-atenderan-en-emergencia

14. Martin, H.P., \& Schumann, H. (1996). Die Globalisierungsfalle. Hamburg: Rororo Sachbuch.

15. Nino, C. S. (1989). La filosofía del control judicial de constitucionalidad. Revista del Centro de Estudios Constitucionales, 4, 79-88.

16. Rajland, B. (2018). Estado y globalización: ¿desaparición del Estado o reestructuración de 
funciones? En El Estado y la globalización. Buenos Aires: EDIAR.

17. RT. (2018). El modelo portugués para acabar con las drogas. Disponible en: https://actualidad.rt.com/ actualidad/260438-politica-drogas-portugal

18. Vigo, R. (2007). El iusnaturalismo actual de $M$. Villey a J. Finnis. México: Fontamara.

19. von Hayek, F. A. (2011). Camino de servidumbre. Madrid: Unión Editorial.

20. von Mises, L. E. (1995). La mentalidad anticapitalista. Madrid: Unión Editorial.

21. Weber, M. (2014). Economía y Sociedad. Esbozo de sociología comprensiva. México: Fondo de Cultura Económica.

22. Zaffaroni, E. R. (2015). El Derecho Latinoamericano en la fase superior del colonialismo. Buenos Aires: Madres de la Plaza de Mayo.

23. Zaffaroni, E. R., \& Días Dos Santos, ílison D. (2019). La nueva crítica criminológica. Criminología en tiempos de totalitarismo financiero. Quito: El Siglo. 